\title{
Arbor
}

\section{La mujer galerista, marchante del s. XX, impulsora de grandes hombres}

\section{M. ${ }^{a}$ José de los Ángeles Sanz}

Arbor CLXVIII, 663 (Marzo 2001), 365-370 pp.

Galerista se supone que es la persona hombre o mujer que dirige una GALERIA DE ARTE, aunque antiguamente también se llamaba así al soldado que iba en barcos galeras que cruzaban todos los continentes, y que se encargaba de proteger las provisiones destinadas a la manutención de todos los navegantes.

GALERÍAS, tienen su origen cuando en los suntuosos palacios renacentistas y romanos guardaban sus obras de arte en unas grandes salas, decoradas para este fin, esta acepción dio lugar a la voz inglesa de Gallery, cuando solamente se dedican a pintura entonces recibe el nombre de PINACOTECA.

El crecimiento del arte ha sido tan espectacular que incluso ha implicado al comercio como salas de exposiciones o lo que es lo mismo galerías; que yá no solamente son lugares donde se venden obras de arte, sino que se coleccionan, se difunden y sobre todo se exponen para deleite de los autenticos virtuosos del arte. El problema que está siempre presente en la galería, es que los impuestos són altisimos sobre todo lo que se refiere a la importación; por esta misma razón muchas de las galerías del mundo habren sus puertas en Francia o Alemania donde sus impuestos son considerablemente más bajos que sí tuvieran que negociar en sus propios países.

En España las normativas vigentes no favorecen al crecimiento del mercado del arte, los galeristas se enemistan con los artistas porque no están de acuerdo con las retenciones, avales... etc. y esto se incrementa considerablemente cuando se trata de pintores extranjeros.

En nuuestro país hay aproximadamente un millar de galerías, pero un $70 \%$ solamente se dedica a vender arte, porque se complementan con objetos de regalo, antiguedades, artículos de librería o marcos. 
No todas las provincias españolas tienen el mismo número de galerías, a la cabeza están Madrid y Barcelona, aunque también Valencia tiene un mercado cosiderable, la situación gegrafica influye enormemente, pues suelen agruparse en zonas dedicadas al mismo fín.Anualmente se celebran alrededor de 5000 exposiciones, y es la galería quien selecciona a los artistas con preferencia de los yá consagrados y solamente un $10 \%$ que son poco conocidos tienen oportunidad de colgar sus óleos, acuarelas u obra gráfica; también hay galerías que tienen sus preferencias en cuanto a los temas desde pintura antigua a las más modernas corrientes vanguardistas.

En cuanto a las galerías internacionales, el tema es diferente pues no suelen tener sus propietarios en exclusiva sino que suelen ser un grupo de inversores, o empresarios donde se manejan unas cifras astronómicas, la relación entre el artista y el director artístico de estas poderosísimas empresas es el Marchante, que más que comerciante es un defensor del arte, por eso la aparición de este personaje se hace necesaria cuando el artista no tiene medios para darse a conocer por él mismo y es él quien se encarga de valorar y defender las obras de arte $\mathrm{y}$ en resumen es el representante independiente entre el artista y el cliente.

Llevo algún tiempo dirigiendo galerías de arte,cuyo comienzo fue en la «Galería 10» situada en pleno corazón de una zona donde predominan salas dedicadas a exponer pintura

Mi primera exposición fue la presentación de un gran pintor argentino, con unas cualidades extraordinarias, su pintura figurativa cuenta con la magia del color, su reunión entre el cielo y el mar en la distancia es de una belleza extraordinaria,.tres años mas tarde volví a reclamar su presencia en la galería que actualmente dirijo, Miguel Angel Guerreiro, se está afianciando más y mas en su brillante carrera ascendente.

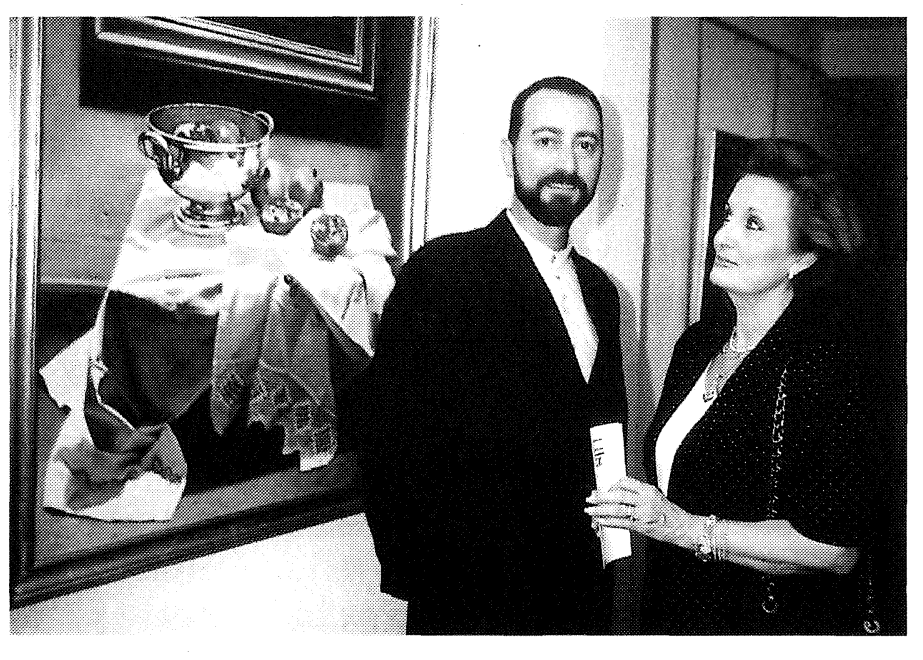

MIGUEL ÁNGEL GUERREIRO. 
La mujer galerista, merchante del s. XX, impulsora de...

Durante la primavera del año 1994 y en la citada «Galería 10» tuve el honor de tener expuesta la obra de Oswaldo Guayasamin gran pintor ecuatoriano, una de las figuras más importantes de la América latina, aunque su mensaje es universal; su pintura transmite con una fuerza extraordinaria, la visión dolorosa de la injusticia social en el mundo; al admirar sus cuadros se identifica uno con aquellos que defienden y luchan por la libertad. Se prodigaron sus dibujos, su obra gráfica, y algún óleo y en todos ellos estaban presentes las expresiones drámaticas de sus figuras y ese colorido magistral que imprime en to-

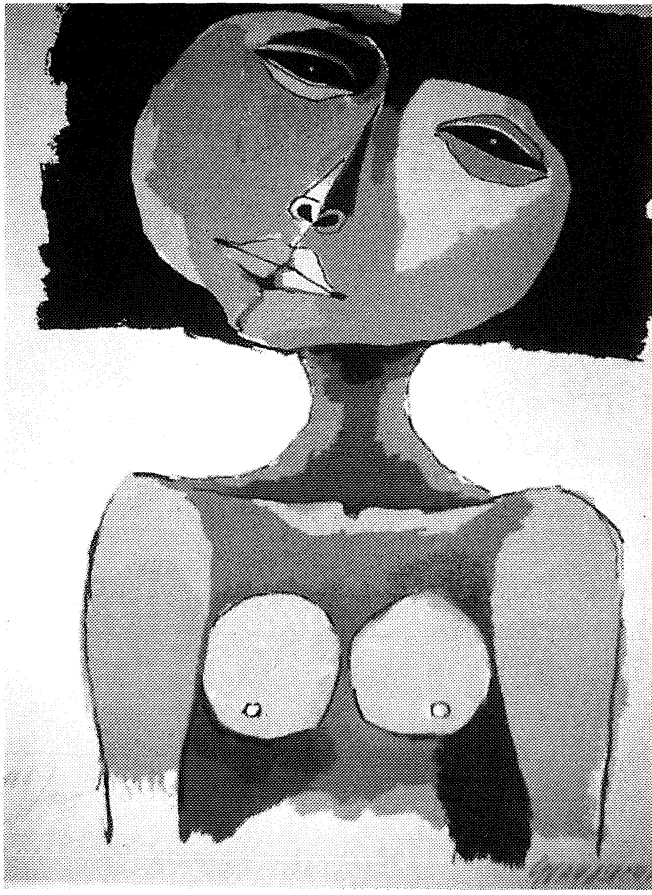

OSWALDO GUAYASAMIN. das ellas.

Hace tres años tomé las riendas de la Galería de arte del Club Cultural Zayas y mi experiencia hasta el momento ha sido altamente positiva, por ella han desfilado pintoras y pintores de diversas tendencias y estilos diferentes. Realmente y en términos generales la mayoría de los artistas no necesitaban un impulso grande por parte de la galerista, pues yá estaban consagrados, y otros mas noveles se han prodigado menos en exposiciones y posiblemente su presencia en nuestra Galería haya servido de salto para futuras expresiones artísticas.

Entre los pintores que durante estos tres años han estado mostrando su obra con nosotros citaré a los siguientes:

Carlos Abad su profesión no tiene nada que ver con su auténtica vocación que es la pintura, pintor realista y figurativo que representa con un rigor enorme, los edificios, las calles de diferentes ciudades y sus colores blancos y grises hacen un contraste digno de admirar.

José Diaz: mi amistad de muchos años con él me facilitó el que se decidiera traer su obra al Zayas,como buen bohemio no tenía en su pensamiento exponer a corto plazo y mi poder de persuasión hizo el milagro. Pintor consagrado que en este caso fue su personalidad quién dio impulso a la Galería, aunque manchego de nacimiento profesionalmente se 
formó en París cuna del arte en toda su magnitud, allí se codeó con los mas grandes pintores de su generación, aunque ha sido y es un virtuoso de las artes en sus diferentes modalidades y se ha sabido rodear de hombres importantesde la literatura, la música, el teatro... y hasta los toros pues sus amigos eran grandes toreros Antonio Bienvenida, Paco Camino, etc.

Hablar de las cualidades artísticas de este gran pintor, me llevaría páginas y páginas interminables; sus cuadros están concebidos según unos ritmos rigurosos dignos de nombrar,

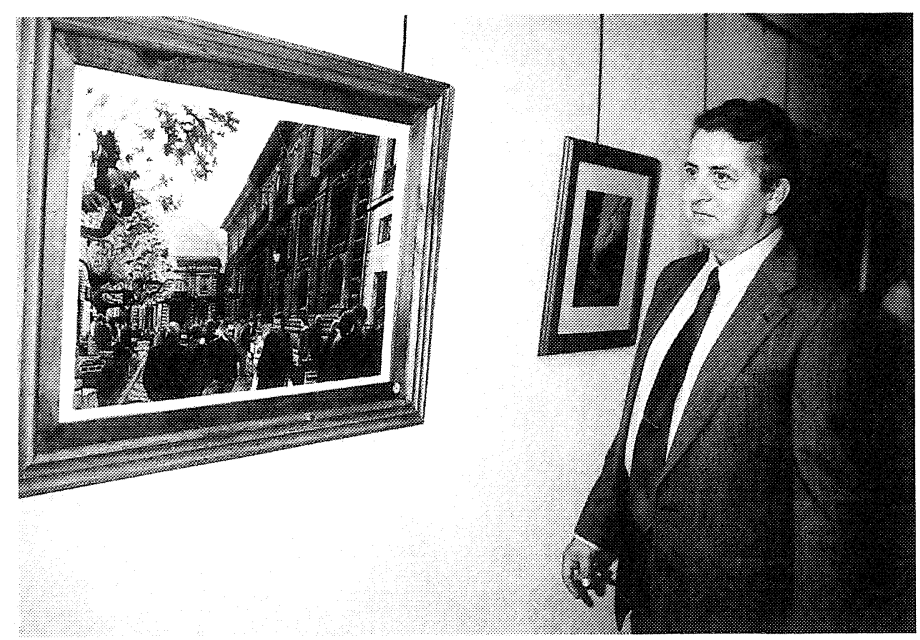

CARLOS ABAD.
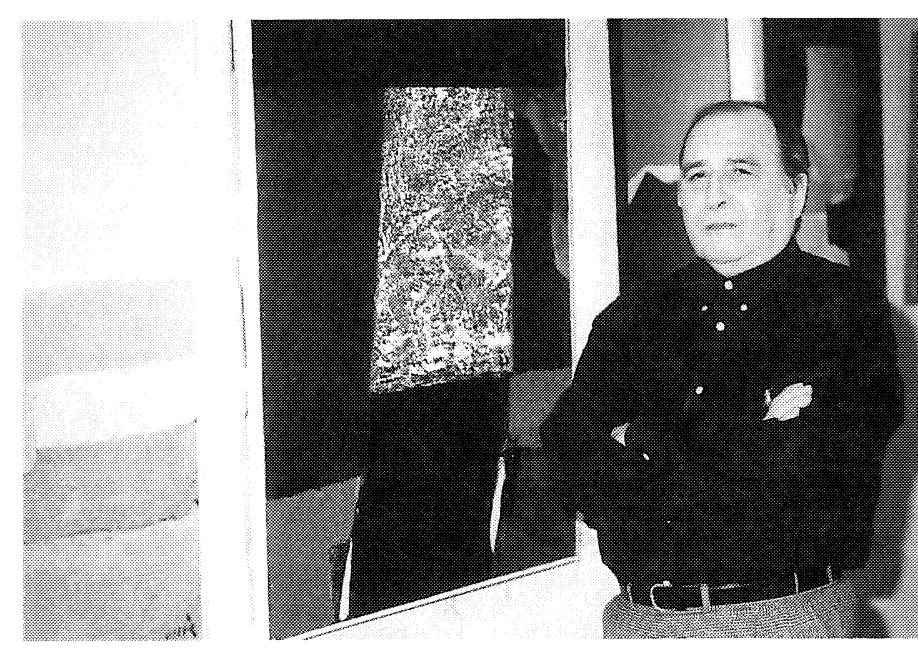

JOSÉ DÍAZ sus maravillosas meninas de Velázquez desde diferentes creaciones, sus escenas taurinas de un realismo y un dramatismo sobrecogedor... es en resumen un artista genial, también como persona tiene un toque de genialidad que podemos dar fé todos los amigos que le admiramos y sobre todo que le queremos.

Antonio Arias: Como madrileño que soy, y que todo el tema pictórico que representa el Madrid de principio de siglo me apasiona, encontré en este artista un pintor sensacional, representa como nadie los motivos castizos de Madrid de aquella época, sus chulapas y chulapos son de un realismo que da la impresión de que pueden salirse de sus cuadros... sus co- 
La mujer galerista, merchante del s. XX, impulsora de...

rralas... tan representadas en famosísimas zarzuelas... tabernas típicas que desafortunadamente han desaparecido o estan a punto de hacerlo.

Es curioso como este pintor tan identificado con el Madrid castizo, pasó parte de su vida en París donde se formó profesionalmente y donde participó activamente de la corriente pictórica de esos momentos. El paso por nuestra Galería ha sido muy positivo y aunque era muy popular y sobretodo muy conocido, cada vez mas gente ha visitado nuestra sala y sus ccuadros se han difundido más, el impulso está servido.

Las Galerías están abiertas a cualquier tendencia y aunque bien es verdad que la nuestra se ha inclinado por la pintura figurativa, también hemos contado con artistas de gran renombre $y$ sus extraordinarias Vanguardias, tal es el caso de Pedro Fuentes pintor muy joven pero con una carrera ascendente importante, que primero expuso en solitario y después compartió nuestra sala con otro gran pintor, de su

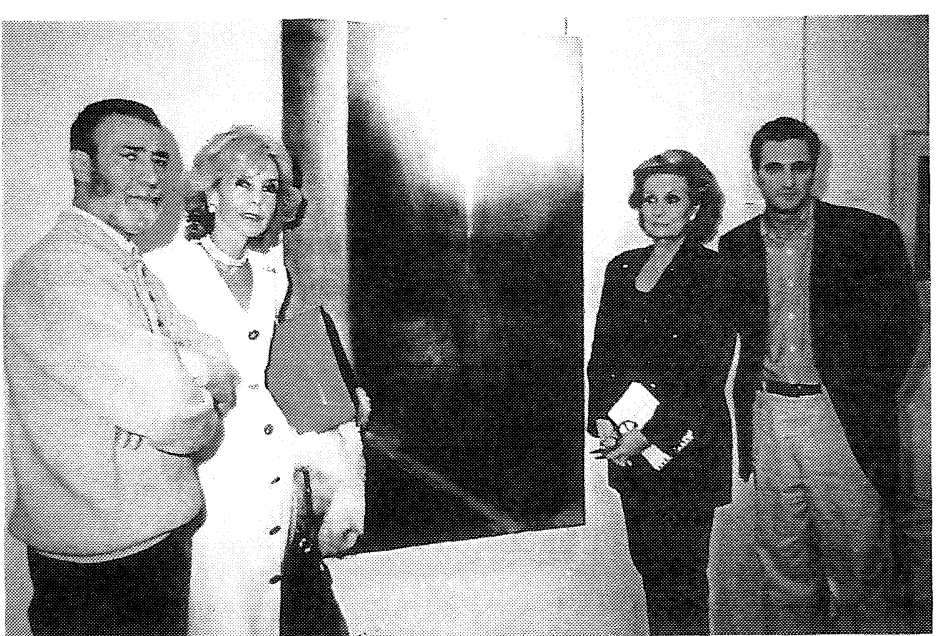

SEGUNDO GÁMEZ Y PEDRO FUENTES. misma corriente Segundo Gámez mayor que el anterior, y con un currículum interesante y una experiencia de años triunfando en su profesión, maneja el color con una soltura y una fuerza admirable, sorprendiendo enormemente cada vez que sus cuadros son expuestos que llegan a alcanzar el cenit, pero con la seguridad que la próxima vez será todavia mejor.

Muy reciente la última exposición de un pintor sevillano, «Diego Rafael», sus cuadros con unos temas de ambiente andaluz como sus conocidos balcones cuajados de flores o sus ventanas repletas de macetas tan típicas de la zona, aborda igualmente El Rocío que tanto ha vivido el artista, las carretas adornadas magníficamente con un realismo que sólo pueden testificar quienes también lo han vivido.

Paralelamente al desfile del pintor hombre, me he volcado con la mujer pintora; he conocido pintoras magníficas y siempre he dado las mismas oportunidades que a ellos, porque de todos es sabido que a la hora 
de exponer en una galería la balanza se inclina por el pintor, pero la mujer necesita un impulso en el mundo del arte que hasta poco tiempo no tenía; y no digamos sí nos remontamos a la Antigüedad hubiera sido inconcebible una pintora alternando pictóricamente con Velázquez o el Greco, por ello la difusión que merece la mujer pintora me parece de justicia porque aunque en menor número que hombres, hay artistas femeninas extraordinarias y que pueden equipararse al hombre pintor. 